\title{
Pt-CoOx nanoparticles supported on ETS-10 for preferential oxidation of $\mathrm{CO}$ reaction
}

\author{
Angela López, Nuria Navascues, Reyes Mallada*, Silvia Irusta* \\ Nanoscience Institute of Aragon and Chemical and Environmental Engineering Department, \\ University of Zaragoza, 50018 Zaragoza, Spain \\ *Corresponding authors
}

\begin{abstract}
In this paper we prepare bimetallic Pt-CoOx nanoparticles which are further supported in microporous titanosilicate ETS-10. This support has been previously demonstrated as a good candidate for this reaction in the presence of $\mathrm{CO}_{2}$ and $\mathrm{H}_{2} \mathrm{O}$. The bimetallic nanoparticles and the supported catalysts containing different loadings of nanoparticles have been extensively characterized and tested in the PROX reaction. The characterization of the nanoparticles discarded the formation of a metallic alloy, although Co and Pt are intimately in contact in the nanoparticle as the HAADF-STEM images revealed. XPS confirmed that the calcined nanoparticles would consist of metallic platinum and cobalt and Pt oxides. The catalyst containing 1.4 wt.\% of PtCo nanoparticles can achieve complete CO conversion in the temperature range $120-150 \circ \mathrm{C}$ working at WHSV $=30 \mathrm{~L} \mathrm{~h}^{-1} \mathrm{~g}^{-1}$.
\end{abstract}

Key words: Bimetallic catalyst, PtCo nanoparticles, PROX, ETS-10 


\section{Introduction}

Among the many approaches to reduce $\mathrm{CO}$ concentration in the reformed gas mixture to the levels required for the use in low temperature Proton Exchange Membranes Fuel Cell (PEMFC), preferential catalytic oxidation of $\mathrm{CO}$ to $\mathrm{CO}_{2}$ (PROX) has been considered as the most promising [1]. An efficient catalyst for this reaction should convert $\mathrm{CO}$ avoiding the competing oxidation of $\mathrm{H}_{2}$. In fact, such an ideal catalyst should convert $\mathrm{CO}$ molecules in the presence of a large excess of $\mathrm{H}_{2}$, together with other components that can negatively affect the activity, like $\mathrm{H}_{2} \mathrm{O}$ or $\mathrm{CO}_{2}$ [2]. Typical reformate gas compositions at the exit of the water gas shift reactor include $15-20$ vol. $\% \mathrm{CO}_{2}, 0.5-2$ vol.\% $\mathrm{CO}$ and about $15-25$ vol.\% $\mathrm{H}_{2} \mathrm{O}$ and $\mathrm{H}_{2}$ in high concentrations [3]. Due to the presence of these molecules in the reactor feed, the influence of $\mathrm{H}_{2} \mathrm{O}$ and $\mathrm{CO}_{2}$ on Pt group catalysts on different supports has been studied. On Pt-Co catalysts supported on alumina it was found that the presence of water showed a positive effect on CO conversion but only below $120^{\circ} \mathrm{C}$ [4]. When aluminumphosphates were used as support a slight negative effect of $\mathrm{CO}_{2}$ on $\mathrm{CO}$ conversion was ascribed to the adsorption on the active sites for activating oxygen. In this case water also was found to have a negative effect on CO conversion probably because of the adsorption on the support [5]. Since the discovery of ETS-10 and ETS-4 by Kuznicki [6] these titanosilicates have attracted increasing interest and they have been studied extensively. In particular ETS-10 presents high capacity ion exchange isomorphic substitution and low acidity. We have previously studied the effect of water and $\mathrm{CO}_{2}$ on Pt-ETS-10 catalysts[3] and a strong inhibition on CO conversion was observed after the introduction of $\mathrm{CO}_{2}$. This was explained by taking into account the basic nature of ETS-10 that gives rise to a strong interaction with $\mathrm{CO}_{2}$, a reactant of acid nature. However, in the presence of water this effect was completely reversed. The water favored the formation of surface $\mathrm{OH}$ groups, which enhanced the Brønsted acidity of ETS-10 and compensates the strong inhibition 
effect of $\mathrm{CO}_{2}$. These observations make ETS-10 a good candidate as support for PROX reaction in the presence of water and $\mathrm{CO}_{2}$.

It is known that Pt catalysts are excellent for hydrogen oxidation, but in the presence of $\mathrm{CO}$ it is inhibited due to the strong $\mathrm{CO}$ adsorption and high $\mathrm{CO}$ coverage hindering the available sites for hydrogen and oxygen adsorption and further dissociation [7]. With increasing temperature the $\mathrm{CO}$ coverage decreases and the hydrogen oxidation starts competing for oxygen. The modification of the surface electronic structure and chemical properties on Pt, by the introduction of other subsurface $3 \mathrm{~d}$ transition metals, was theoretically demonstrated at the beginning of this century by Kitchin et al.[8]. Since then the preparation and study of Pt bimetallic catalyst has grown exponentially and several reviews have been published in this field recently $[9,10]$. To enhance the activity in the PROX reaction several non-noble metals have been added to the Pt catalysts such as $\mathrm{Co}, \mathrm{Ni}, \mathrm{Cu}, \mathrm{Fe}, \mathrm{Mn}, \mathrm{Sn}[1]$, which clearly increase the activity of platinum in this reaction, among them Co and Fe seem to be the most promising.

The addition of cobalt to Pt nanoparticles on different supports was found to improve the catalytic activity for the PROX of CO $[4,5,11-16]$. However only some of the catalysts were tested under simulated reformate streams containing all the components $[4,5,11,15]$. There is a debate about the active phase in these catalysts for PROX. The group of Komatsu claimed that the active phase corresponds to the $\mathrm{Pt}_{3} \mathrm{Co}$ intermetallic compound $[11,17]$. On the contrary Xu et al. proposed an architecture of the Pt-Co bimetallic catalyst consisting of Pt nanoparticles decorated with highly dispersed CoO nanostructures [18].

The reported Pt-Co catalysts tested in the PROX reaction were prepared by simultaneous or successive impregnation of precursor salts on the support followed by thermal treatments $[4,5,10,11,13,15]$. By employing recent methods, developed in the field of nanotechnology for the synthesis of colloidal suspensions of metallic nanoparticles, Pt-Co nanoparticles can be 
synthesized in a controlled manner as preformed nanocatalysts before they are applied on support materials. This approach has been followed by several authors for different reactions such as Fischer-Tropsch [19], methanol oxidation reaction [20], $\mathrm{CO}_{2}$ hydrogenation [21] and selective carbonyl reduction in $\alpha, \beta$-unsaturated aldehydes [22]. However, to the best of our knowledge, this strategy has not been pursued for the preparation of bimetallic Pt-Co catalysts tested in PROX reaction.

In this work Pt-Co nanoparticles were synthesized in solution and afterwards supported on microporous titanosilicate ETS-10. The materials were characterized by SEM, TEM, XRD, XPS and tested in PROX in a stream containing carbon dioxide and water besides a high concentration of hydrogen. The goal is to develop a two-step preparation method for controlling the synthesis of the bimetallic active phase, followed by deposition in an appropriate support. Furthermore we will get insight into the catalytic active phase thanks to the characterization of the bimetallic nanoparticles and the catalytic activity tests for different nanoparticle loadings and reaction conditions.

\section{Materials and methods}

\subsection{Nanoparticles synthesis}

The synthesis of the nanoparticles was divided in two successive reduction steps for Co and Pt salts, using $\mathrm{NaBH}_{4}$ as reducing agent. The synthesis was performed at $0^{\circ} \mathrm{C}$ under $\mathrm{N}_{2}$ atmosphere to avoid any oxidation. This procedure is based on a synthesis protocol previously reported by Du et al [23]. In a typical synthesis $0.5 \mathrm{~g}$ of PVP (MW=10000, Sigma-Aldrich) were dissolved in $100 \mathrm{~mL}$ of ethanolic solution $3.6 \mathrm{mM}$ in $\mathrm{CoCl}_{2}$ (Sigma-Aldrich, anhydrous, purity

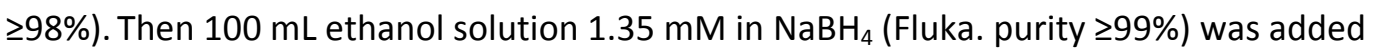
dropwise. The mixture color changes from blue to brown indicating the formation of metallic cobalt nanoparticles. After that, $100 \mathrm{~mL}$ of $10.8 \mathrm{mM} \mathrm{H}_{2} \mathrm{PtCl}_{6}$ (Sigma-Aldrich. purity $\geq 99 \%$ ) ethanol solution was added and the resultant mixture was stirred for 30 minutes. Finally the Pt 
was reduced adding $100 \mathrm{~mL}$ of $8.1 \mathrm{mM} \mathrm{NaBH}_{4}$ (Fluka. purity $\geq 99 \%$ ) ethanol solution dropwise. The mixture was kept under stirring for 3 hours at $0^{\circ} \mathrm{C}$ and finally ethanol was evaporated at $85^{\circ} \mathrm{C}$. Part of the synthetized nanoparticles were calcined $3 \mathrm{~h}$ at $500^{\circ} \mathrm{C}$ before characterization analysis.

\subsection{Supported PtCo nanoparticles on ETS-10}

The ETS-10 support was synthesized using anatase as titanium source according to the procedure previously described [24]. The molar gel composition corresponds to 4.4 $\mathrm{Na}_{2} \mathrm{O}: 1.4 \mathrm{~K}_{2} \mathrm{O}: \mathrm{TiO}_{2}: 5.5 \mathrm{SiO}_{2}: 125 \mathrm{H}_{2} \mathrm{O}$. The gel was prepared dissolving $\mathrm{NaCl}$ (Merck, purity 299\%) and $\mathrm{KCl}$ (Merck, purity 99.5\%) in deionized water under stirring. Then sodium silicate (Merck $28.5 \% \mathrm{SiO}_{2} ; 8.5 \% \mathrm{Na}_{2} \mathrm{O}$ ) was added slowly to the solution. After stirring for 3 hours, $\mathrm{KF}$ (Merck, purity 98.5\%) and $\mathrm{TiO}_{2}$ anatase (Sigma-Aldrich, purity $\geq 99.7 \%$ ) were added. The solution was kept under stirring for one hour. The $\mathrm{pH}$ was adjusted to 10.4 using $\mathrm{HCl}$ to avoid impurities such as ETS-4 and AM-3 [25]. The obtained gel was introduced in an autoclave at $230^{\circ} \mathrm{C}$ for $24 \mathrm{~h}$. After that the solids were recovered by filtration, washed with deionized water and dried at $100^{\circ} \mathrm{C}$.

The synthesized PtCo nanoparticles were incorporated to the support by incipient wetness impregnation method. The synthetized nanoparticles were dispersed in a volume of water enough to fill the porous of the support and put in contact with the ETS-10. The prepared catalysts are hereafter named as XNP/ETS, where " $\mathrm{x}$ " denotes the nanoparticles loading in $w t \%$.

\subsection{Characterization}

The morphology, composition and particle size of nanoparticles, support and catalysts were characterized by Scanning Electron Microscope, SEM coupled with EDX detector, (FEI InspectF50) and Transmission Electron Microscopy, TEM, (FEI Tecnai F30) operated at $300 \mathrm{kV}$. 
For TEM observations the samples were dispersed in ethanol in an ultrasonic bath for 15 minutes and deposited on a carbon grid. X-ray diffraction patterns were obtained in a PANalytical Empyrean equipment in Brag Bentano configuration using CuK $\alpha$ radiation and equipped with a PIXcel ${ }^{1 \mathrm{D}}$ detector, to identify the crystalline phases.

The bulk chemical composition of digested samples was analyzed using microwave plasma atomic emission spectrometry (Agilent $4100 \mathrm{MP}-\mathrm{AES}$ ). The solid samples were digested in aqua regia for 20 minutes in an autoclave heated at $200{ }^{\circ} \mathrm{C}$ in a microwave oven (Ethos Plus, Mileston).

The X-ray photoelectron analysis (XPS) was performed with an Axis Ultra DLD (Kratos Tech.). The spectra were excited by the monochromatized AlK $\alpha$ source (1486.6 e.V) run at $15 \mathrm{kV}$ and $10 \mathrm{~mA}$. For the individual peak regions, pass energy of $20 \mathrm{eV}$ was used. Survey spectrum was measured at $160 \mathrm{eV}$ pass energy. Analyses of the peaks were performed with the CasaXPS software, using a weighted sum of Lorentzian and Gaussian components curves after background subtraction.

Catalytic activity tests

The activity measurements were carried out using fixed-bed reactor configuration in a quartz tube of $9 \mathrm{~mm}$ internal diameter. The reactor was loaded with $100 \mathrm{mg}$ of catalyst and $200 \mathrm{mg}$ of quartz, used as a diluent. The reaction temperature was measured with a thermocouple located in the center of the catalyst bed. The composition of the feed stream was: $1 \% \mathrm{CO}$, $1 \% \mathrm{O}_{2}, 3 \% \mathrm{H}_{2} \mathrm{O}, 21 \% \mathrm{CO}_{2}$ and hydrogen balance. Prior to catalytic activity tests, the solids were heated at $5 \stackrel{\circ}{\circ} / \mathrm{min}$ up to $500 \stackrel{\circ}{ } \mathrm{C}$ in air and kept at this temperature for $3 \mathrm{~h}$. Then the catalyst was cooled down to room temperature under $\mathrm{N}_{2}$ atmosphere.

Feed and products were analyzed by gas chromatography with a Varian CP-4900 Micro-GC equipped with two modules containing, molecular sieve and PPQ columns respectively and using helium as carrier gas. Under the analysis conditions the detection limit of CO was $5 \mathrm{ppm}$. 
The CO conversion, oxygen conversion and the selectivity of the PROX reaction were calculated according to:

CO conversion $(\%)=\frac{\text { FCO feed }-\mathrm{FCO} \text { outlet }}{\text { FCO feed }} * 100$

$\mathrm{O}_{2}$ conversion $(\%)=\frac{\mathrm{FO} 2 \text { feed }-\mathrm{FO} 2 \text { outlet }}{\mathrm{FO} 2 \text { feed }} * 100$

Selectivity $(\%)=\frac{\text { FCO feed }-\mathrm{FCO} \text { outlet }}{2 *(\mathrm{FO} 2 \text { feed }-\mathrm{FO} 2 \text { outlet })} * 100$

The conversion values were obtained after the reactor temperature was stable for at least 30 $\min$ and the values reported represent the average of 3 samples taken at the reactor exit. Calculate selectivity gives the percentage of oxygen moles consumed for $\mathrm{CO}$ oxidation. $\mathrm{CH}_{4}$ was not detected in any of the experiments carried out. The mass balance was measured and was always in the range $98-102$ at.\%.

\section{Results}

\subsection{Pt-Co nanoparticles characterization}

Figure 1 shows the TEM images (a) and particle size histogram (b) of the synthesized nanoparticles. The particles have spherical shape with diameter distribution obtained by measuring 100 particles in different images of $3.2 \pm 0.6 \mathrm{~nm}$. HAADF-STEM elemental mapping images clearly show that Pt and Co atoms are distributed throughout the whole particle (Figure $1 \mathrm{c}$ ). The coexistence of Pt and Co elements in the particles was further confirmed by the EDS analysis (Figure $1 \mathrm{~d}$ ).

The bulk atomic Pt to Co ratio obtained by MP-AES analysis was $3.0 \pm 0.04$. On the other hand, SEM-EDX and XPS gave values of $2.4 \pm 0.6$ and $1.7 \pm 0.2$ respectively. Due to the different surface sensitivity of both techniques and comparing with the bulk composition, these results suggest that most of the cobalt could be on the surface of the nanoparticles.

Figure 2 displays the XRD pattern of the calcined nanoparticles. The diffraction pattern exhibits peaks in the 20-120 range corresponding to the platinum cubic structure, Fm-3m (JCPDS 01- 
080-3827). It was previously reported that the $\mathrm{Pt}_{3} \mathrm{Co}$ alloy formation would shift the Pt peaks to higher angles due to the incorporation of Co into the cubic structure and the concomitant lattice contraction $[11,26,27]$. Since no shift was observed, the incorporation of Co to the platinum lattice can be ruled out, even when both elements coexist in the same particle according to STEM results and it is known that they could form a continuous series of solids solutions [28]. Considering that no diffraction peaks of cobalt or its oxides were detected in the synthesized particles, most of Co species are possibly either amorphous [29, 30] or with crystallite size smaller than the technique detection limit. The crystallite size of Pt was calculated through Debye Scherrer formula using the full width at half-maximun of the Pt(111) diffraction peak. The value obtained for the Pt crystallite was $2.2 \mathrm{~nm}$ which is similar to the measured values by TEM for the nanoparticles, see Figure 1. The difference with TEM results could be because XRD reflects the crystal grain size rather than the actual particle morphology [31]. Beside the mentioned signals, peaks related to $\mathrm{NaCl}$ can be observed, these crystals would be formed from the synthesis salts since chlorides are use as metal precursors and the reduction agent is a sodium salt.

XPS analysis of the bimetallic particles revealed the presence of carbon, cobalt, platinum, oxygen, sodium and chlorine. The binding energies were referenced to the internal C 1s ( 284.9 eV) standard (Figue $1 \mathrm{SI}$ ). Since the size of the nanoparticles prevents the purification of samples by centrifugation, all the compounds that are not eliminated by calcination at $500 \circ \mathrm{C}$ remain in the final product (i.e., $\mathrm{NaCl}$ also detected by XRD).

The Pt $4 \mathrm{f}$ XPS spectrum of the synthesized particles can be fitted by three pairs of doublets (Figure 3a). The branching ratio was kept at the statistical value. The binding energies of the first Pt $4 \mathrm{f}_{7 / 2}$ component was located at $71.1 \mathrm{eV}$ assigned to metallic platinum [32]. By measuring the relative peak areas, the percentage of $\mathrm{Pt}^{0}$ species in the nanoparticles is calculated to be $43 \%$. The other $\mathrm{Pt} 4 \mathrm{f}_{7 / 2}$ components at 71.8 and $74.2 \mathrm{eV}$ were ascribed to PtO and $\mathrm{PtO}_{2}$ [33]. Figure $3 \mathrm{~b}$ shows the $\mathrm{Co} 2 \mathrm{p}$ core level with multiple peaks due to the spin orbital 
splitting and final state features (shake-up satellites) of the $3 d^{6}$ and $3 d^{7} \underline{L}$ lines electronic structure for $\mathrm{Co}^{3+}$ and $\mathrm{Co}^{2+}$ in different cobalt oxide modification [34]. The $\mathrm{Co} 2 \mathrm{p}_{3 / 2}$ region was fitted with two peaks at 779.7 and $781 \mathrm{eV}$ that were assigned to $\mathrm{Co}^{2+}$ and $\mathrm{Co}^{3+}$ oxidation states respectively [35]. The broad and low intensity satellite structure is due to the overlapping of the two satellites, typical for the $\mathrm{Co}_{3} \mathrm{O}_{4}$ spinel. The measured atomic ratio $\mathrm{Co}^{2+} / \mathrm{Co}^{3+}$ was 1.33 , showing an excess of $\mathrm{Co}^{2+}$ (57 at.\%). The presence of metallic or alloyed cobalt in the nanoparticles can be ruled out due to the absence of a signal at lower binding energy (778.5 eV) $[32,36]$. Even when the bulk Pt/Co atomic ratio is 3, XPS gives no evidence of the presence of $\mathrm{Pt}_{3} \mathrm{Co}$ phase. According to XPS results the calcined nanoparticles would consist of metallic platinum and cobalt and Pt oxides.

\subsection{Supported CoPt-NPs on ETS-10}

TEM images of PtCo/ETS-10 catalysts show the presence of well dispersed nanoparticles, with size in the 3 to $4 \mathrm{~nm}$ range, on the surface of the ETS-10 crystals (Figure 4). There is a small increase in the calculated mean particle size after deposition on the support, from $3.5 \pm 0.5 \mathrm{~nm}$ in the $0.35 \mathrm{NP} / \mathrm{ETS}$ catalysts to $3.8 \pm 0.6 \mathrm{~nm}$ in $1.20 \mathrm{NP} / \mathrm{ETS}$ solid and $4.0 \pm 0.7 \mathrm{~nm} 1.40 \mathrm{NP} / \mathrm{ETS}$. The surface of the calcined solids was analyzed by XPS (Figure 2a SI), besides the adventitious carbon, the ETS-10 components $\mathrm{Si}, \mathrm{Ti}, \mathrm{O}$ and the cations $\mathrm{Na}$ and $\mathrm{K}$ were detected. Analysis of $\mathrm{Ti}$ $2 p$ spectrum (Figure $2 \mathrm{~b} \mathrm{SI}$ )reveals that the binding energy is characteristic of octahedrally coordinated Ti atoms in ETS-10 [24]. The presence of sodium would be associated not only to the support but to de $\mathrm{Cl}$ also detected on the surface of catalysts.

\subsection{Catalytic activity}

The influence of space velocity on the catalytic behavior of 1.4NP/ETS was studied. CO conversion and $\mathrm{CO}_{2}$ selectivity are shown in Figure 5 as a function of the catalyst bed temperature at different WHSVs. This behavior was fully reproduced in subsequent cycles of temperature increasing/decreasing indicating that after 30 min under reaction stream the catalysts reached their stable condition. In all cases, as the reactor temperature increased, the 
CO conversion increases, reaches a maximum at an optimum temperature and then decreases. It can be observed that the conversion curves shift to higher temperature with increasing the space velocity. At a WHSV of $120 \mathrm{~L} \mathrm{~g}^{-1} \mathrm{~h}^{-1}$, this optimum temperature was $224^{\circ} \mathrm{C}$, corresponding to a CO conversion of $84 \%$. As the WHSV decreased to 60 and then to 30 $\mathrm{L} \mathrm{g}^{-1} \mathrm{~h}^{-1}$, the optimum temperatures shifted to 174 and $125 \mathrm{C}$ respectively, but in these cases the complete CO conversion was achieved. For the lower WHSV the $100 \%$ CO conversion was maintained in a $25^{\circ} \mathrm{C}$ operating window from 125 to $150^{\circ} \mathrm{C}$. As expected the selectivity for the highest conversions was around $50 \%$.

The CO PROX performance of catalysts with different nanoparticles loading is compared in Figure 6. Working at WHSV $=30 \mathrm{Lg}^{-1} \mathrm{~h}^{-1}$ in all the solids $100 \% \mathrm{CO}$ conversion was achieved. As expected the increase in the nanoparticles load from $0.35 \mathrm{wt} \%$ to 0.78 and $1.20 \mathrm{wt} \%$ shifted the CO conversion curve to lower temperatures. Further increase of the nanoparticles loading to $1.40 \mathrm{wt} \%$ improves the catalytic behavior reaching the complete CO conversion at $125 \stackrel{\circ}{ } \mathrm{C}$. The decrease in CO conversion at higher temperatures occurs due to oxygen scarcity caused by acceleration of undesirable concurrent hydrogen oxidation reaction mentioned before which results in a selectivity decrease [13]. It is important to notice that all the catalysts, except the $0.35 \mathrm{NP} / \mathrm{ETS}$ exhibit $25^{\circ} \mathrm{C}$ operating window where the concentration of $\mathrm{CO}$ is below the detection limit

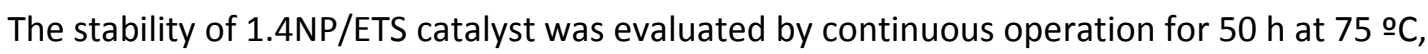
with a WHSV of $30 \mathrm{Lg}^{-1} \mathrm{~h}^{-1}$, the results are presented in Figure 7. A conversion level of around $30 \%$ with a selectivity of $70 \%$ was maintained for more than 50 hours, even in the presence of water and carbon dioxide.

\section{Discussion}

Pt-Co catalysts obtained by deposition of synthesized Pt-Co nanoparticles on ETS-10 with low platinum loading (1.4 wt\%) achieve the complete CO conversion at $125 \stackrel{\circ}{ } \mathrm{C}$, working at WHSV= 
$30 \mathrm{~L} \mathrm{~g}^{-1} \mathrm{~h}^{-1}$ in presence of water and $\mathrm{CO}_{2}$. This activity was maintained for $50 \mathrm{~h}$ on reaction stream. In the literature there are works reporting the activity in the presence of $\mathrm{H}_{2} \mathrm{O}$ and $\mathrm{CO}_{2}$ of Pt-Co catalysts with low Pt loading. Ko et al. [16] reported a Pt-Co catalyst (0.5\%Pt-Co/YSZ, $\mathrm{Co} / \mathrm{Pt}=10$ ) that maintains the concentration of $\mathrm{CO}$ in the outlet stream lower than $10 \mathrm{ppm}$ of CO in the range of 100 to 150 ㅇ $\mathrm{C} \%$ working at $16.7 \mathrm{~L} \mathrm{~g}^{-1} \mathrm{~h}^{-1}$ a much lower space velocity than the used in this work.

A solid with $1 \mathrm{wt} \% \mathrm{Pt}$ and $2 \mathrm{wt} \%$ Co supported on cobalt modified AlPO-5 also presented total CO conversion in the range $110-125^{\circ} \mathrm{C}$ also at a WHSV slightly lower than the used in this work $\left(24 \mathrm{~L} \mathrm{~g}^{-1} \mathrm{~h}^{-1}\right)$, besides the stability of the catalysts was not tested [5]. On the other hand, Yan et al. [4] worked at WHSV $40 \mathrm{~L} \mathrm{~g}^{-1} \mathrm{~h}^{-1}$, higher than ours, in a catalyst with $1 \mathrm{wt} \% \mathrm{Pt}$ and $3 \mathrm{wt} \%$ Co supported on alumina obtaining $100 \%$ CO conversion at 120 ㄷ, in this case the stability was also no reported. Finally Wang et al. [11] reported complete removal of $\mathrm{CO}$ at temperatures ranging from 40 to $150 \circ \mathrm{C}$ and $30 \mathrm{~L} \mathrm{~g}^{-1} \mathrm{~h}^{-1}$ with an optimized catalyst containing a load of Pt as high as $4 \%$ and $0.7 \%$ Co supported on carbon nanotubes. Summing up the activity results presented in this work, with preformed PtCo NPs supported on ETS-10 are among the best reported literature values.

Komatsu and Tamura [11] claim that the active species for PROX at low temperatures in Pt-Co supported on silica are $\mathrm{Pt}_{3} \mathrm{Co}$ and $\mathrm{PtCo}$. However, the catalysts loaded with $3 \mathrm{wt} \% \mathrm{Pt}$, were tested in absence of water and carbon dioxide. Even when the bulk atomic ratio in the prepared nanoparticles was $\mathrm{Pt} / \mathrm{Co}=3$, no evidences of any intermetallic compound was found in our catalysts (XPS and XRD results) suggesting that $\mathrm{Pt} / \mathrm{CoO}$ is the active specie in a typical reformate gas stream .On YSZ supported Pt-Co solids, the high activity was attributed to the presence of isolated Pt-Co nanoparticles interacting with the support [16]. Because of the good particles dispersion observed in TEM images, the good catalytic performance of $1.4 \mathrm{NP} / \mathrm{ETS}$ could be associated to isolated Pt-Co nanoparticles. On the other hand, HAADF-STEM mapping 
of particles confirm the presence of both Pt and Co in the same particle, these would favor the synergistic interaction between metallic Pt and CoO (XPS results) promoting the high CO-PROX performance of PtCoNP/ETS catalysts [12, 18]. Another interesting characteristic of our catalysts is the presence of $\mathrm{Na}$, not only as exchange ion in the support, but also remaining from the synthesis process. It is known that sodium enhances the PROX activity of platinumcobalt catalyst up to a sodium content of $2 \mathrm{wt} \%$ [37]. The effect of the sodium addition would be related to the promotion of oxygen adsorption on platinum, lowering the temperature regions in which carbon monoxide adsorption does not inhibit the adsorption of oxygen. The positive effect of sodium would be more important than the possible negative effect of chlorine blocking the sites which are able to activate the $\mathrm{CO}$ molecule that was found for Pt/ceria catalysts [38].

\section{Conclusions}

Pt-Co catalysts were obtained by deposition of synthesized Pt-Co nanoparticles consisting of metallic platinum and cobalt and Pt oxides (Pt/Co bulk atomic ratio=3) on ETS-10 support. The catalysts showed high activity for the selective oxidation of $\mathrm{CO}$ in a simulated reformate gas stream with high hydrogen concentration (74 vol\%). The solid containing $1.4 \mathrm{wt} \%$ of nanoparticles can achieve complete CO conversion in the temperature range $120-150$ ㅇ C working at WHSV $=30 \mathrm{~L} \mathrm{~h}^{-1} \mathrm{~g}^{-1}$. The stability of this solid was tested for $50 \mathrm{~h}$, showing no changes in CO conversion or selectivity. The activity of the prepared catalysts would be related to the good dispersion of the nanoparticles on the support, the presence of $\mathrm{CoO}$ on the surface of $\mathrm{Pt}$ nanoparticles and the beneficial presence of sodium.

\section{Acknowledgements}

Financial support from MINECO (Spain) PRI-PIBAR-2011-1349 is acknowledged. The microscopy works have been conducted in the "Laboratorio de Microscopias Avanzadas" at "Instituto de 
Nanociencia de Aragon - Universidad de Zaragoza". Authors acknowledge the LMA-INA for offering access to their instruments and expertise. 


\section{References}

[1] K. Liu, A. Wang, T. Zhang, ACS Catalysis 2 (2012) 1165-1178.

[2] S. Rico-Francés, E.O. Jardim, T.A. Wezendonk, F. Kapteijn, J. Gascon, A. SepúlvedaEscribano, E.V. Ramos-Fernandez, Applied Catalysis B: Environmental 180 (2016) 169-178.

[3] V. Sebastian, S. Irusta, R. Mallada, J. Santamaría, Applied Catalysis A: General 366 (2009) 242-251.

[4] J. Yan, J.X. Ma, P. Cao, P. Li, Catalysis Letters 93 (2004) 55-60.

[5] C. Wang, L. Zhang, Y. Liu, Applied Catalysis B-Environmental 136 (2013) 48-55.

[6] S.M. Kuznicki, New crystalline titanium silicate molecular sieve zeolite/ with defined $\mathrm{X}=$ ray powder diffraction pattern, as adsorbent and catalyst, Engelhard Minerals Corp; Engelhard Corp, 1989.

[7] P.V. Snytnikov, V.D. Belyaev, V.A. Sobyanin, Kinetics and Catalysis 48 (2007) 93-102.

[8] J.R. Kitchin, J.K. Nørskov, M.A. Barteau, J.G. Chen, Journal of Chemical Physics 120 (2004) 10240-10246.

[9] S. Zafeiratos, S. Piccinin, D. Teschner, Catalysis Science and Technology 2 (2012) 17871801.

[10] W. Yu, M.D. Porosoff, J.G. Chen, Chemical Reviews 112 (2012) 5780-5817.

[11] T. Komatsu, A. Tamura, Journal of Catalysis 258 (2008) 306-314.

[12] C. Wang, B. Li, H. Lin, Y. Yuan, Journal of Power Sources 202 (2012) 200-208.

[13] D.I. Potemkin, E.Y. Filatov, A.V. Zadesenets, P.V. Snytnikov, Y.V. Shubin, V.A. Sobyanin, Chemical Engineering Journal 207-208 (2012) 683-689.

[14] E.Y. Ko, E.D. Park, K.W. Seo, H.C. Lee, D. Lee, S. Kim, Journal of Nanoscience and Nanotechnology 6 (2006) 3567-3571.

[15] C. Kwak, T.J. Park, D.J. Suh, Chemical Engineering Science 60 (2005) 1211-1217.

[16] E.Y. Ko, E.D. Park, H.C. Lee, D. Lee, S. Kim, Angewandte Chemie - International Edition 46 (2007) 734-737.

[17] S. Furukawa, K. Ehara, T. Komatsu, Catalysis Science and Technology 6 (2016) 16421650.

[18] H. Xu, Q. Fu, X. Guo, X. Bao, ChemCatChem 4 (2012) 1645-1652.

[19] D.O. Silva, L. Luza, A. Gual, D.L. Baptista, F. Bernardi, M.J.M. Zapata, J. Morais, J. Dupont, Nanoscale 6 (2014) 9085-9092.

[20] H. Huang, Y. Fan, X. Wang, Electrochimica Acta 80 (2012) 118-125.

[21] S. Alayoglu, S.K. Beaumont, F. Zheng, V.V. Pushkarev, H. Zheng, V. lablokov, Z. Liu, J. Guo, N. Kruse, G.A. Somorjai, Topics in Catalysis 54 (2011) 778-785.

[22] S.C. Tsang, N. Cailuo, W. Oduro, A.T.S. Kong, L. Clifton, K.M.K. Yu, B. Thiebaut, J. Cookson, P. Bishop, Acs Nano 2 (2008) 2547-2553.

[23] X. Du, M. Inokuchi, N. Toshima, Journal of Magnetism and Magnetic Materials 299 (2006) 21-28.

[24] B.M. Faroldi, E.A. Lombardo, L.M. Cornaglia, S. Irusta, Applied Catalysis a-General 417 (2012) 43-52.

[25] L. Lv, F.B. Su, X.S. Zhao, Microporous and Mesoporous Materials 76 (2004) 113-122.

[26] S. Fu, G. Yang, Y. Zhou, H.-B. Pan, C.M. Wai, D. Du, Y. Lin, Rsc Advances 5 (2015) 3268532689.

[27] G.-H. Wang, J. Hilgert, F.H. Richter, F. Wang, H.-J. Bongard, B. Spliethoff, C. Weidenthaler, F. Schüth, Nat Mater 13 (2014) 293-300.

[28] A.S. Darling, Platinum Metals Reviews 7 (1963) 96-104.

[29] J.-N. Zheng, L.-L. He, C. Chen, A.-J. Wang, K.-F. Ma, J.-J. Feng, Journal of Power Sources 268 (2014) 744-751.

[30] J.R.C. Salgado, E. Antolini, E.R. Gonzalez, Applied Catalysis B: Environmental 57 (2005) 283-290. 
[31] B. Li, Z. Yan, Q. Xiao, J. Dai, D. Yang, C. Zhang, M. Cai, J. Ma, Journal of Power Sources 270 (2014) 201-207.

[32] J. Xu, X. Liu, Y. Chen, Y. Zhou, T. Lu, Y. Tang, Journal of Materials Chemistry 22 (2012) 23659-23667.

[33] M. Asteazaran, S. Bengio, W.E. Triaca, A.M. Castro Luna, Journal of Applied Electrochemistry 44 (2014) 1271-1278.

[34] S. Schmid, R. Hausbrand, W. Jaegermann, Thin Solid Films 567 (2014) 8-13.

[35] E. Demirci, M. Öztürk, E. Sınır, U. Ulucan, N. Akdoğan, O. Öztürk, M. Erkovan, Thin Solid Films 550 (2014) 595-601.

[36] X. Yu, W. Yu, H. Li, S.-T. Tu, Y.-F. Han, Applied Catalysis B: Environmental 140-141 (2013) 588-597.

[37] C. Kwak, T.J. Park, D.J. Suh, Applied Catalysis A: General 278 (2005) 181-186.

[38] E.O. Jardim, S. Rico-Frances, F. Coloma, J.A. Anderson, J. Silvestre-Albero, A. SepulvedaEscribano, Journal of Colloid and Interface Science 443 (2015) 45-55. 


\section{Figure captions}

Figure 1: a) TEM image of synthesized Pt-Co nanoparticles, b) particle size histogram, c) HAADF-STEM mapping of one particle, d) EDX analysis of particle.

Figure 2: XRD pattern of the synthesized nanoparticles after calcination at 500 ㅇ. .

Figure 3: a) Pt4f and b) Co2p core level of PtCo nanoparticles after calcination at 500ㄷ.

Figure 4: TEM images and particle size distribution of a) and b) $0.35 \mathrm{NP} / \mathrm{ETS}$; c) and d) 1.20NP/ETS; e) and f) $1.40 \mathrm{NP} / \mathrm{ETS}$.

Figure 5: $\mathrm{CO}$ conversion and $\mathrm{CO}_{2}$ selectivity versus temperature for $1.40 \mathrm{NP} / \mathrm{ETS}$ catalysts at different WHSV $\left(\mathrm{L}^{-\mathrm{h}^{-1}} \mathrm{~g}^{-1}\right)$. Filled symbols correspond to first heating cycle and empty symbols cooling down cycle.

Figure 6: Conversion of $\mathrm{CO}$ (filled symbols) and ppm of $\mathrm{CO}$ at the outlet (empty symbols) versus temperature for catalysts with different NPs loading: $\nabla \nabla 0.35 \mathrm{NP} / \mathrm{ETS}, 00.78 \mathrm{NP} / \mathrm{ETS}$, $\Delta \triangle 1.2 \mathrm{NP} /$ ETS $\square \square 1.4 \mathrm{NP} / \mathrm{ETS}$. Empty symbol are for decreasing temperature; b) CO outlet in ppm versus temperature $(\stackrel{\circ}{ } \mathrm{C}) \mathrm{WHSV}=30 \mathrm{~L} / \mathrm{h} \mathrm{g}$.

Figure 7: CO Conversion and selectivity versus time at $75 \stackrel{\circ}{\circ}$ for $1.40 \mathrm{NP} / \mathrm{ETS}$ catalyst. WHSV $=$ $30 \mathrm{~L} \mathrm{~h}^{-1} \mathrm{~g}^{-1}$ 
Figure 1

a)

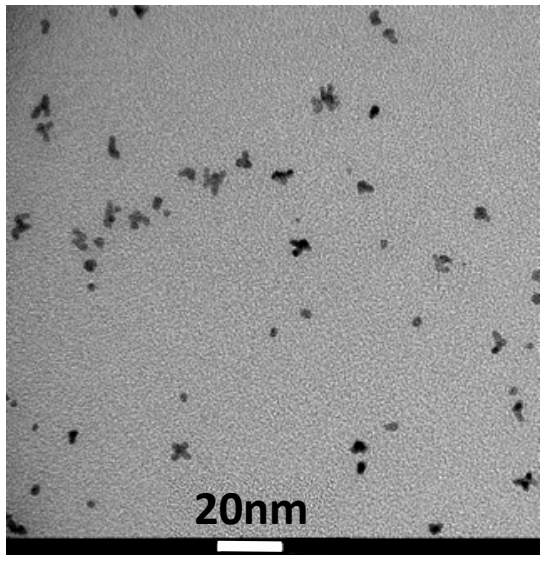

c)

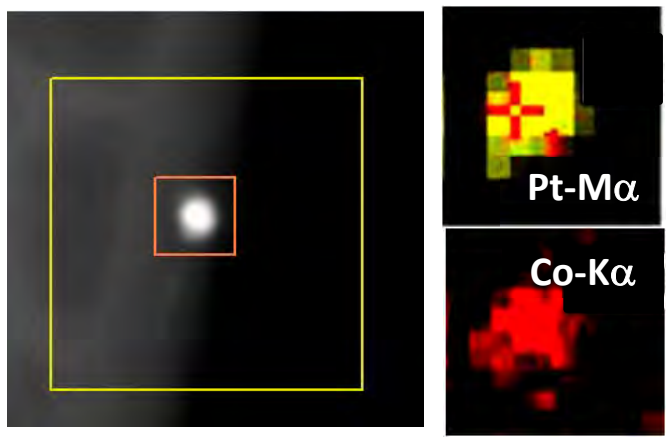

b)

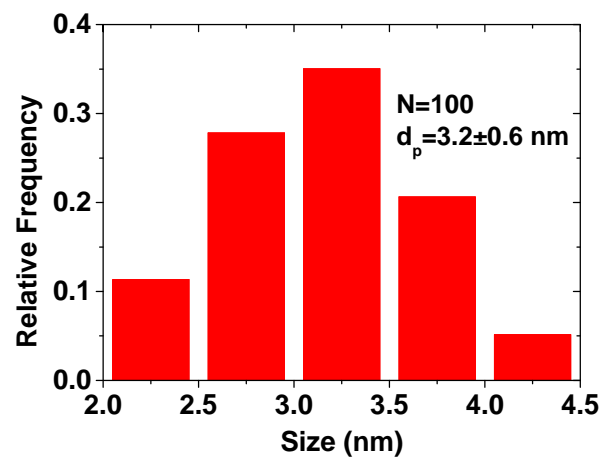

d) 
Figure 2

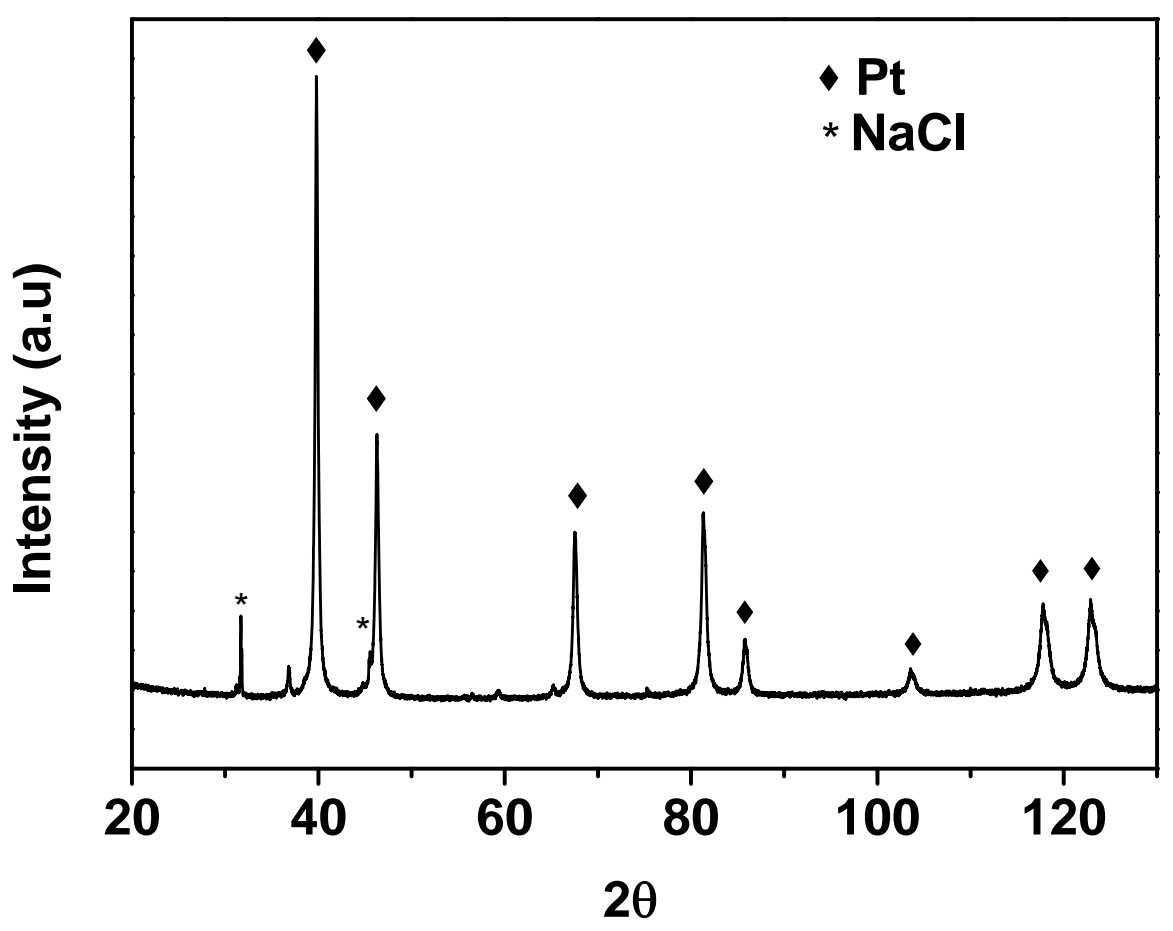


Figure 3

a)

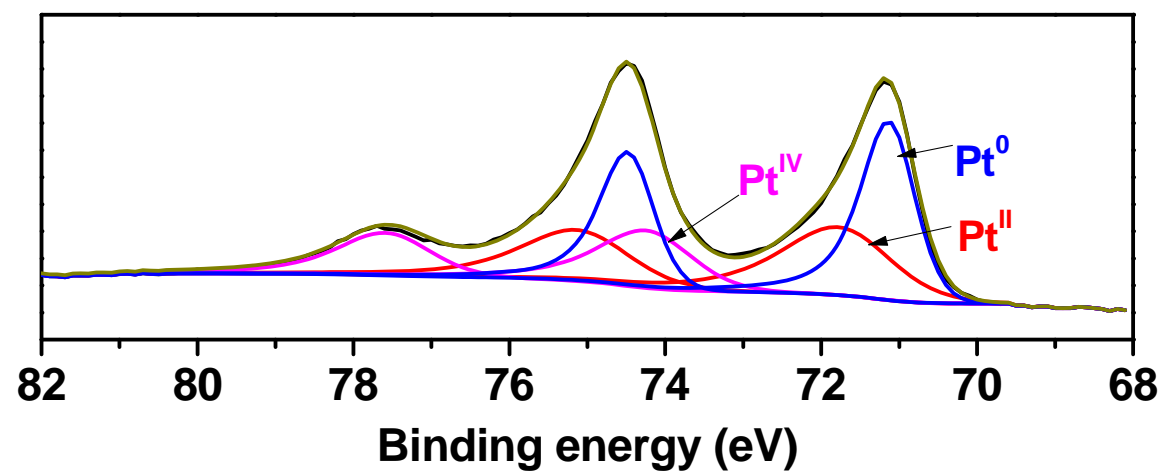

b)

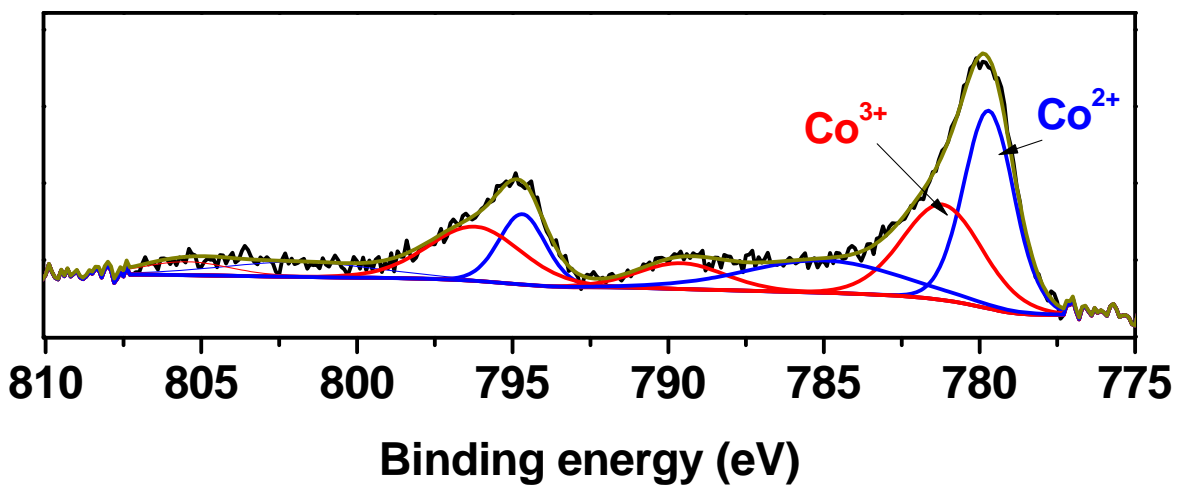


Figure 4
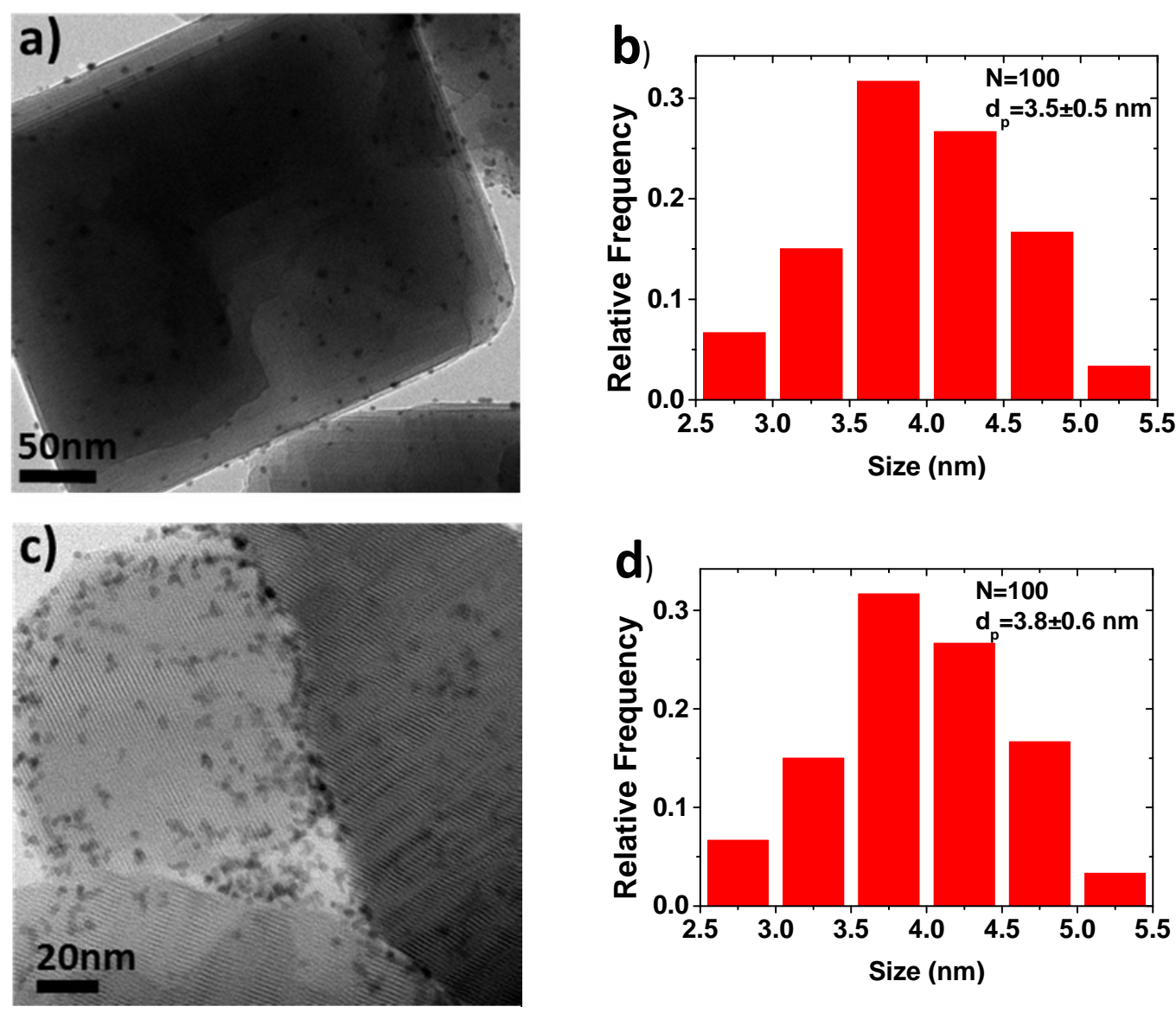

e)

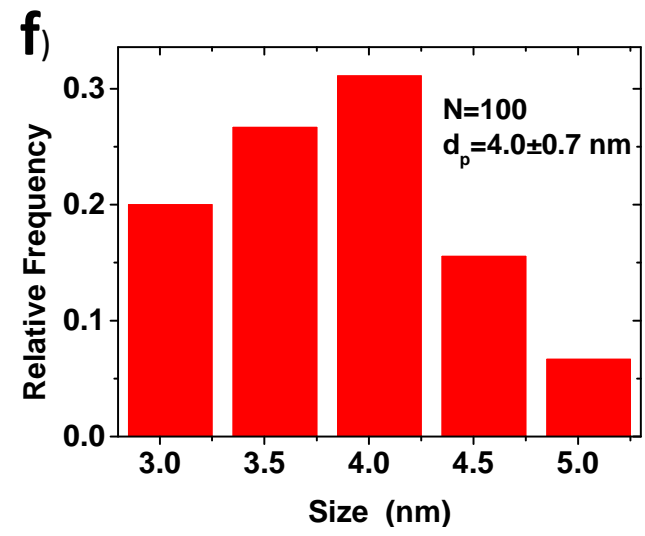


Figure 5

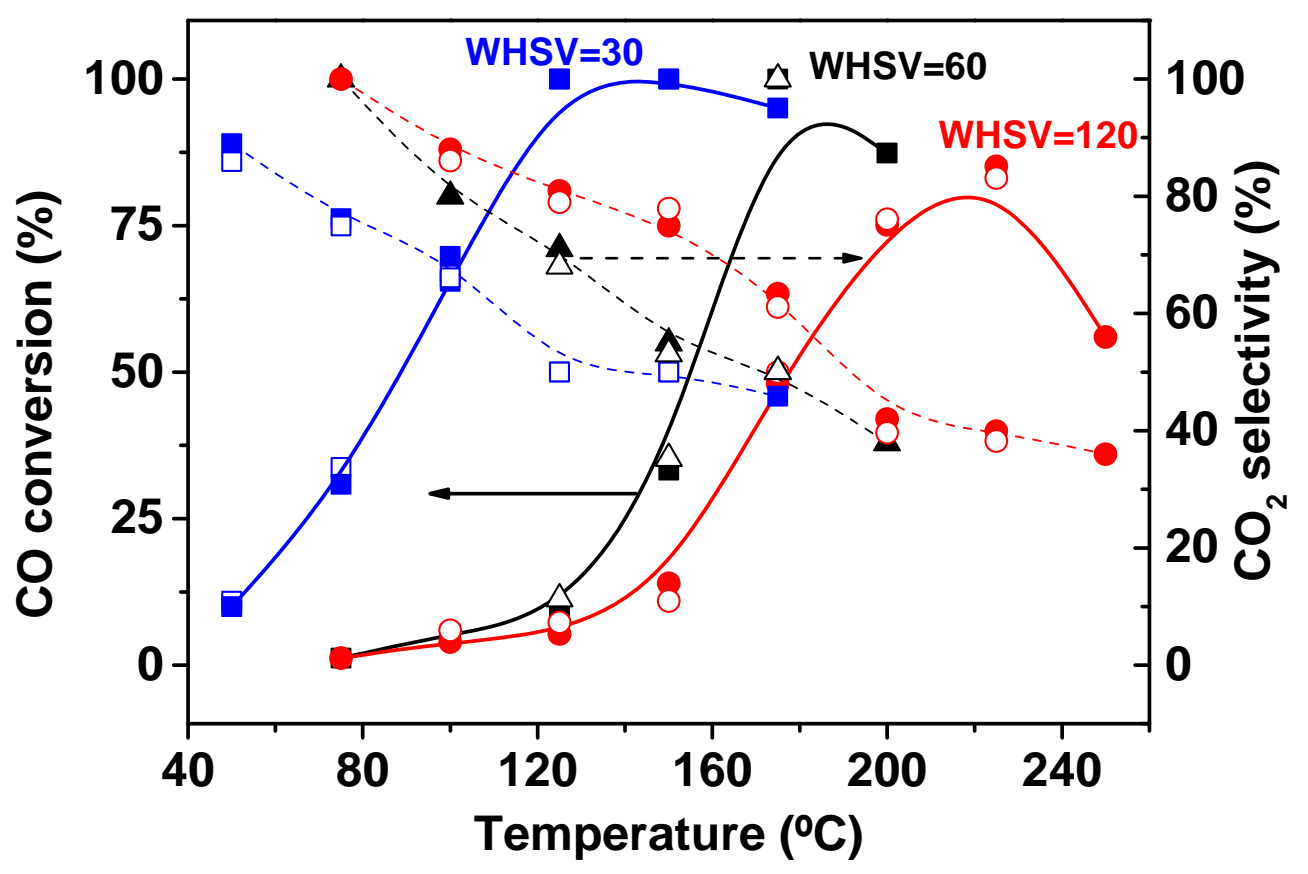


Figure 6

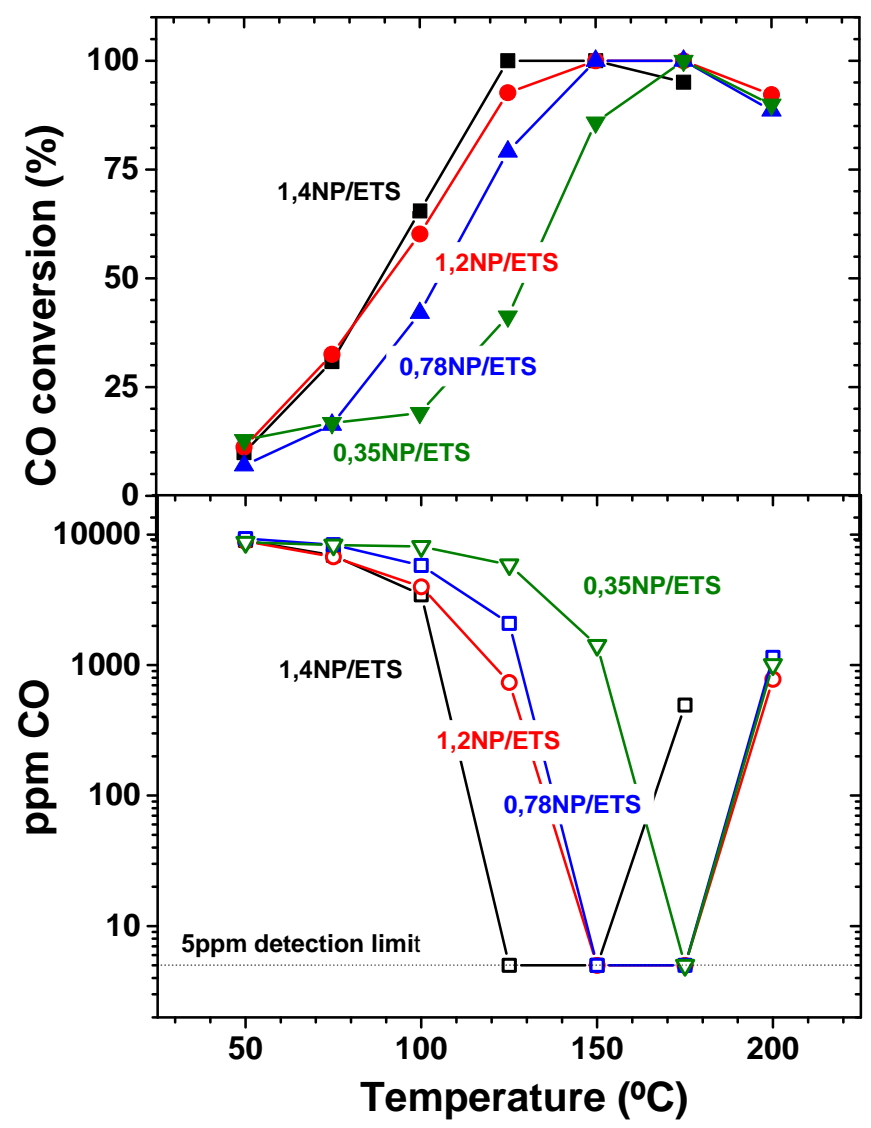


Figure 7

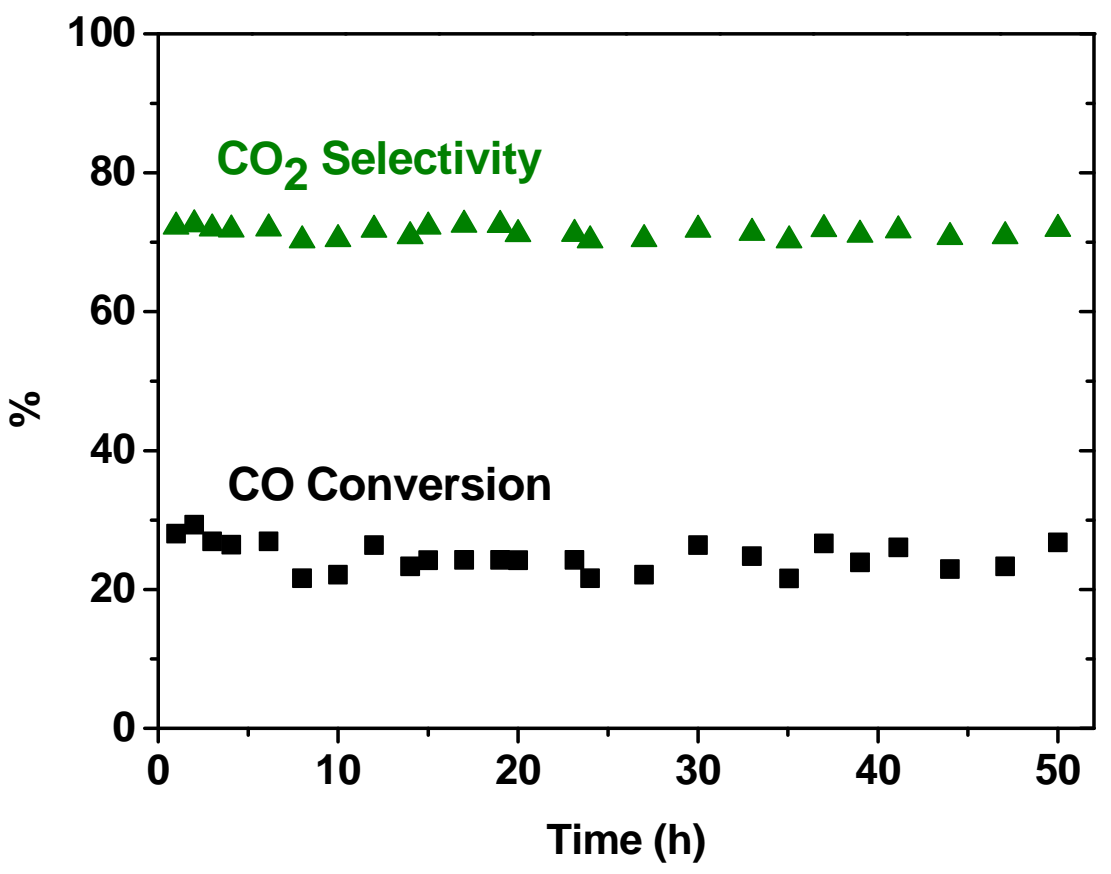

